\title{
LA ILEGÍTIMA MUTACIÓN DE LA CONSTITUCIÓN POR EL JUEZ CONSTITUCIONAL Y LA DEMOLICIÓN DEL ESTADO DE DERECHO EN VENEZUELA
}

\author{
ALLAN R. BREWER-CARÍAS
}


SUMARIO

I. LA SUPREMACÍA CONSTITUCIONAL, LAS MODIFICACIONES A LA CONSTITUCIÓN SÓLO CON APROBACIÓN POPULAR Y EL SISTEMA DE JUSTICIA CONSTITUCIONAL. II. LA ILEGÍTIMA REFORMA DE LA CONSTITUCIÓN, DESPUÉS DE SU APROBACIÓN POR EL PUEBLO, POR LA MISMA ASAMBLEA NACIONAL CONSTITUYENTE QUE LA SANCIONÓ Y SU LEGITIMACIÓN POR EL JUEZ CONSTITUCIONAL. III. LA ILEGÍTIMA MUTACIÓN EFECTUADA POR EL JUEZ CONSTITUCIONAL DE LOS EFECTOS DE LOS REFERENDOS REVOCATORIOS DE CARGOS DE ELECCIÓN POPULAR. IV. LA ILEGÍTIMA MUTACIÓN EFECTUADA POR EL JUEZ CONSTITUCIONAL DEL RANGO SUPRA CONSTITUCIONAL DE LOS TRATADOS EN MATERIA DE DERECHOS HUMANOS. V. LA ILEGÍTIMA MUTACIÓN EFECTUADA POR EL JUEZ CONSTITUCIONAL DEL PRINCIPIO DE ALTERNABILIDAD REPUBLICANA, LA ENMIENDA CONSTITUCIONAL PARA ESTABLECER LA REELECCIÓN INMEDIATA Y CONTINUA DE LOS FUNCIONARIOS ELECTOS, Y LA MODIFICACIÓN DE LOS EFECTOS DEL RECHAZO POPULAR A REFORMAS CONSTITUCIONALES. VI. LA ILEGÍTIMA MUTACIÓN CONSTITUCIONAL EFECTUADA POR EL JUEZ CONSTITUCIONAL RESPECTO DE LA PROHIBICIÓN DEL FINANCIAMIENTO PÚBLICO A LAS ACTIVIDADES DE LOS PARTIDOS POLÍTICOS. APRECIACIÓN FINAL. 


\title{
LA ILEGÍTIMA MUTACIÓN DE LA CONSTITUCIÓN POR EL JUEZ CONSTITUCIONAL Y LA DEMOLICIÓN DEL ESTADO DE DERECHO EN VENEZUELA
}

POR

\author{
ALLAN R. BREWER-CARÍAS \\ Profesor de la Universidad Central de Venezuela \\ Adjunct Professor of Law, Columbia Law School
}

\section{Un lejano y afectuoso recuerdo}

Muy pocas personas saben que mi actividad académica de investigación la comencé efectivamente en 1960, cuando aún estudiaba tercer año de la carrera de derecho de la Facultad de Derecho de la Universidad Central de Venezuela. Ese año, Manuel García Pelayo, quien en 1958 había sido recién nombrado Director del Instituto de Estudios Políticos en la misma Facultad, me ofreció que colaborara con él, como auxiliar de investigación, en la búsqueda, síntesis y ordenación de la información relativa a los acontecimientos más relevantes en política internacional, con destino a la sección informativa de la naciente Revista Politeia que editó el Instituto. Me correspondió, así, durante varios meses revisar bajo su instrucción, entre otras, la edición diaria del The New York Times, y presentarle los resúmenes correspondientes de noticias sobre tales eventos. Desde allí pude entonces seguir y sistematizar, con el detenimiento de quien realiza un con- 
cienzudo trabajo, lo que acaecía en el mundo, oportunidad que, si duda, pocos jóvenes de 20 años y con otros intereses, quizás puedan tener. ${ }^{1}$

Pero lo cierto es que allí comencé mi formación como investigador, leyendo, comprendiendo, analizando, seleccionando, resumiendo, haciendo fichas y sistematizando los datos requeridos; y además, en forma única, colaborando con el profesor García Pelayo, con cuyo libro sobre Derecho Constitucional Comparado en la edición de la Revista de Occidente, ya me había topado, pues que era de lectura obligatoria para seguir el curso de derecho constitucional en el primer año de derecho. Desde esa época, y a pesar de la diferencia de edad, tuve la oportunidad de entablar con García Pelayo una franca amistad, aún cuando unos meses más tarde yo pasara a trabajar en el Instituto de Derecho Público de la misma Facultad, bajo la dirección de Antonio Moles Caubet, donde realmente fue que desarrollé toda mi carrera académica posterior. Sin embargo, asistí al Seminario de García Pelayo sobre Historia de las Ideas Políticas en el Instituto, y ello resultó más que enriquecedor, pues allí fue que por primera vez supe, por ejemplo, de Sumeria donde comenzó la Historia, o de Federico II de Suabia, el iniciador del Estado Moderno. Yo fui nombrado Director del Instituto de Derecho Público en 1978, un año antes de que García Pelayo dejara el Instituto de Estudios Políticos, ocasión en la cual pudimos nuevamente compartir en las reuniones del Consejo de Facultad, antes de que viajara a España.

García Pelayo, particularmente durante los sesenta y desde los bastiones del Instituto de Estudios Políticos dirigió las labores de investigación del mismo con sentido universal, mas orientadas hacia la ciencia política y la historia de las

${ }^{1}$ Recuerdo en grandes trazos que 1960 fue el año en el cual obtuvieron independencia muchas antiguas colonias, fundamentalmente africanas, como Togo, Camerún, Sudán, Somalia, Mali, Congo, Ghana, Dahomei, Burkina Fasso, Chad, República Centroafricana, Congo Brazzaville, Gabón, Senegal, Nigeria, Mauritania y Chipre. En esa época, Charles De Gaulle enfrentaba los inicios de la rebelión de los militares en Argelia y de la insurrección de la Colonia contra la política colonial francesa; los países europeos fundaban la OCDE; Irán, Irak, Kuwait, Arabia Saudita y Venezuela fundaban la OPEP; y Guatemala, El Salvador, Nicaragua y Honduras, fundaban el Mercado Común Centro Americano. En ese año, además, el cantón de Ginebra otorgaba el derecho de voto a las mujeres; cuatro agentes del Mossad secuestraban al fugitivo nazi Adolf Eichmann en Buenos Aires; el piloto norteamericano del avión U-2 era sometido a juicio en Moscú; se iniciaba la construcción de la represa de Swann en Egipto; y en Cuba se nacionalizaban las propiedades e intereses de empresas norteamericanas como respuesta al embargo económico que se había decretado sobre la Isla. En otro contexto, en ese mismo año, John F. Kennedy era elegido Presidente de los Estados Unidos de América, el más joven de la historia de ese país con 43 años; el príncipe Norodom Sianouk era designado Jefe de Estado de Cambodia, después de haber sido Primer Ministro, y en Ceilán (Sri Lanka) se elegía a Sirimavo Bandaranaike, como la primera mujer jefe de Estado en la historia. 
ideas políticas, y aún cuando nunca abandonó el derecho constitucional, pocos programas estuvieron orientados hacia esta disciplina jurídica o hacia la particular realidad constitucional venezolana. Algunos de sus colaboradores, sin embargo, como por ejemplo, Francisco Rubio Llorente, tocaron temas de derecho constitucional, como los relativos a la supremacía de la Constitución y a la justicia constitucional, ${ }^{2}$ los cuales García Pelayo sólo trataría posteriormente cuando fue designado Presidente del Tribunal Constitucional español después de la sanción de la Constitución de 1978.

Y fue así que en un artículo suyo sobre "El 'Status' del Tribunal Constitucional», publicado en el primer número de la Revista de Derecho Constitucionaß de Madrid, destacó como de la esencia del Estado constitucional en el mundo contemporáneo, el hecho de «que la Constitución en tanto que norma fundamental positiva, vincula a todos los poderes públicos incluido el Parlamento, y que, por tanto, la Ley no puede ser contraria a los preceptos constitucionales, a los principios de que éstos arrancan, o que se infieren de ellos, y a los valores a cuya realización aspira.» ${ }^{4}$ Por supuesto, la referencia era motivada por la idea clave de que la justicia constitucional, como instrumento para finalizar con el absolutismo del Parlamento, estaba llamada a asegurar la sumisión del Parlamento y de la Ley a la Constitución; pero al referirse la Constitución como vinculante para «todos los poderes públicos,» en esa expresión tenía que estar por supuesto incluido el Tribunal Constitucional, pues si en términos del mismo García Pelayo, se trataba de «un órgano constitucional instituido y directamente estructurado por la Constitución," ${ }^{5}$ a pesar de ser el guardián último de la propia Constitución, el mismo tenía y tiene que estar también sometido a ella. Es decir, si el Tribunal Constitucional, «como regulador de la constitucionalidad de la acción estatal, está destinado a dar plena existencia al Estado de derecho y a asegurar la vigencia de la distribución de poderes establecida por la Constitución, ambos componentes inexcusables, en nuestro tiempo, del verdadero "Estado constitucional, ${ }^{6}$ para ello tiene que adaptarse a lo que la Constitución establece, y someterse a su normativa, estándole vedado mutarla.

En contraste, sin embargo, no ha sido infrecuente que tribunales constitucionales, dado el poder que tienen asignados, lejos de garantizar el Estado de De-

2 Véase Francisco Rubio Llorente, «E1 Tribunal Constitucional alemán», Revista de la Facultad de Derecho, UCV, 18, Caracas 1959; y La Corte Constitucional italiana, Caracas 1966.

3 Véase Manuel García Pelayo, «El 'Status' del Tribunal Constitucional», en Revista Española de Derecho Constitucional, vol. I, No 1, Madrid, 1981.

${ }^{4}$ Idem, p. 18.

5 Idem, p. 15.

${ }^{6}$ Idem, p. 15. 
recho, hayan sido los instrumentos utilizados por regímenes autoritarios para demoler sus bases, y eso es precisamente lo que ha ocurrido en Venezuela en la última década (1999-2009), a la vista del mundo democrático. Dejar constancia de algunos aspectos de este proceso, tan contrario a lo que pensaba García Pelayo, ocurrido en el país donde fijó su residencia y su familia, y donde desarrolló buena parte de sus actividades académicas, es lo que he querido hacer en este trabajo escrito con todo afecto en su homenaje.

\section{LA SUPREMACÍA CONSTITUCIONAL, LAS MODIFICACIONES A LA CONSTITUCIÓN SÓLO CON APROBACIÓN POPULAR Y EL SISTEMA DE JUSTICIA CONSTITUCIONAL}

La Constitución Venezolana de 1999 fue adoptada luego de su sanción por una Asamblea Nacional Constituyente, como manifestación de la voluntad del pueblo expresada como poder constituyente originario en el referendo aprobatorio del 15 de diciembre de 1999.7 El principio de la supremacía constitucional se encuentra incluso formalmente expresado en su artículo 7, lo que implica que la Constitución prevalece y debe prevalecer sobre la voluntad de todos los órganos constituidos del Estado, incluyendo el Tribunal Supremo de Justicia, por lo que su modificación sólo puede llevarse a cabo conforme se dispone en su propio texto, como expresión-imposición de la voluntad popular producto de ese poder constituyente originario.

La contrapartida de la obligación de los órganos constituidos de respetar la Constitución, de manera que el poder constituyente originario prevalezca sobre la voluntad de dichos órganos estatales constituidos, es el derecho constitucional que todos los ciudadanos tienen en un Estado Constitucional, a que se respete la voluntad popular expresada en la Constitución, es decir, el derecho fundamental a la supremacía constitucional. ${ }^{8}$ Nada se ganaría con señalar que la Constitución, como manifestación de la voluntad del pueblo, debe prevalecer sobre la de los órganos del Estado, si no existiere el derecho de los integrantes del pueblo de exigir el respeto de esa Constitución, y además, la obligación de los órganos jurisdiccionales de velar por dicha supremacía.

7 Véase sobre la Constitución de 1999, Allan R. Brewer-Carías, La Constitución de 1999. Derecho Constitucional Venezolano, Editorial Jurídica Venezolana, Caracas 2004, 2 vols.

8 Véase Allan R. Brewer-Carías, «El amparo a los derechos y libertades constitucionales (una aproximación comparativa)» en Manuel José Cepeda (editor), La Carta de Derechos. Su interpretación y sus implicaciones, Editorial Temis, Bogotá 1993, pp. 21-81. 
La supremacía de la Constitución está asegurada mediante la previsión en el mismo texto constitucional, por una parte, de su máximo carácter rígido al disponerse la necesaria e indispensable intervención popular para efectuar cualquier cambio a la Constitución, de manera que sólo el poder constituyente originario del pueblo puede aprobar dichas modificaciones, no existiendo en el texto constitucional poder constituyente derivado alguno; y por la otra, de todo un sistema de justicia constitucional para garantizar dicha supremacía.

En cuanto al sistema institucional para la reforma de la Constitución, en el texto se distinguen tres procedimientos diferentes: la Reforma constitucional, la Enmienda constitucional y la Asamblea Nacional Constituyente. El último medio de la convocatoria por referendo de una Asamblea Nacional Constituyente está dirigido a transformar el Estado, a establecer un nuevo orden jurídico y a reformar íntegramente la Constitución (artículo 347). En cambio, en los casos de los procedimientos de "Reforma Constitucional» y de «Enmienda Constitucional,» los mismos están destinados a introducir reformas al texto sin alterar o modificar la estructura y principios fundamentales de la Constitución (arts. 340 y 342), requiriendo en todo caso, también, de la intervención del pueblo mediante la aprobación popular por referendo de las reformas.

En la Constitución, como se dijo, no se regula «poder constituyente derivado" alguno, y solo hay un "poder constituyente originario» que es el pueblo, el cual tiene que aprobar por referendo tanto la Enmienda como la Reforma Constitucional, o la convocatoria a Asamblea Nacional Constituyente. Es decir en el sistema venezolano, ninguna modificación a la Constitución se puede adoptar sin aprobación popular, ${ }^{9}$ y cualquier modificación de la Constitución efectuada fuera de estos tres procedimientos, es inconstitucional e ilegítima.

En cuanto al sistema de justicia constitucional, la Constitución de $1999^{10}$ como consecuencia de los principios de la supremacía y de la rigidez constitucional, ha establecido todo un sistema de justicia constitucional ${ }^{11}$ de carácter

9 Véase Allan R. Brewer-Carías, «La intervención del pueblo en la revisión constitucional en América latina», en El derecho público a los 100 números de la Revista de Derecho Público 19802005, Editorial Jurídica Venezolana, Caracas 2006, pp. 41-52.

${ }^{10}$ Véase los comentarios a la Constitución en Allan R. Brewer-Carías, La Constitución de 1999. Derecho Constitucional Venezolano, Editorial Jurídica Venezolana, 2 Tomos, Caracas 2004

${ }^{11}$ En cuanto a nuestros trabajos, véase Allan R. Brewer-Carías, El Sistema de Justicia Constitucional en la Constitución de 1999: Comentarios sobre su desarrollo jurisprudencial y su explicación a veces errada, en la Exposición de Motivos, Editorial Jurídica Venezolana, Caracas, 2000; Justicia Constitucional, Tomo VII, Instituciones Politicas y Constitucionales, Editorial Jurídica Venezolana, Caracas, 1996; "La Justicia Constitucional en la Nueva Constitución» en Revista de Derecho Constitucional, No 1, Septiembre-Diciembre 1999, Editorial Sherwood, Caracas, 1999, pp. 35-44; 
mixto o integral ${ }^{12}$, que combina el llamado método difuso con el método concentrado de control de constitucionalidad.

Así, la garantía de la supremacía constitucional se consagra, en primer lugar, mediante la asignación a todos los jueces de la República, en el ámbito de sus respectivas competencias y conforme a lo previsto en la Constitución y en la ley, de la obligación «de asegurar la integridad de la Constitución» (art. 334). Y en segundo lugar, además, mediante la asignación al Tribunal Supremo de Justicia de la tarea de garantizar «la supremacía y efectividad de las normas y principios constitucionales», como «el máximo y último intérprete de la Constitución,» y de velar "por su uniforme interpretación y aplicación» (art. 335). También, la Constitución asigna en concreto a la Sala Constitucional del Tribunal Supremo, la Jurisdicción Constitucional (arts. 266,1 y 336) mediante la cual ejerce el control concentrado de la constitucionalidad de las leyes y demás actos estatales de rango legal. A tal efecto, el artículo 336 de la Constitución atribuye a la Sala Constitucional del Tribunal Supremo de Justicia, como Jurisdicción Constitucional, las siguientes competencias:

1. Declarar la nulidad total o parcial de las leyes nacionales y demás actos con rango de ley de la Asamblea Nacional que colidan con esta Constitución.

\footnotetext{
Allan R. Brewer-Carías, «La justicia constitucional en la Constitución de 1999», en Derecho Procesal Constitucional, Colegio de Secretarios de la Suprema Corte de Justicia de la Nación, A.C., Editorial Porrúa, México 2001, pp. 931-961; publicado también en Reflexiones sobre el Constitucionalismo en América, Editorial Jurídica Venezolana, Caracas, 2001, pp. 255-285; «Instrumentos de justicia constitucional en Venezuela (acción de inconstitucionalidad, controversia constitucional, protección constitucional frente a particulares)», en Juan Vega Gómez y Edgar Corzo Sosa (Coordinadores) Instrumentos de tutela y justicia constitucional Memoria del VII Congreso Iberoamericano de Derecho Constitucional, Instituto de Investigaciones Jurídicas, Serie Doctrina Jurídica, No 99, México 2002, pp. 75-99.

12 En cuanto a nuestros trabajos, véase Allan R. Brewer-Carías, Judicial Review in Comparative Law, Cambridge University Press, Cambridge, 1989; El sistema mixto o integral de control de la constitucionalidad en Colombia y Venezuela, Universidad Externado de Colombia (Temas de Derecho Público No 39) y Pontificia Universidad Javeriana (Quaestiones Juridicae No 5), Bogotá 1995; publicado también en Revista Tachirense de Derecho, Universidad Católica del Táchira, N 5-6, San Cristóbal, enero-diciembre 1994, pp. 111-164; en Anuario de Derecho Constitucional Latinoamericano, Fundación Konrad Adenauer, Medellín-Colombia 1996, pp. 163-246; y en G. J. Bidart Campos y J. F. Palomino Manchego (Coordinadores), Jurisdicción Militar y Constitución en Iberoamérica, Libro Homenaje a Domingo García Belaúnde, Instituto Iberoamericano de Derecho Constitucional (Sección Peruana), Lima 1997, pp. 483-560.
} 
2. Declarar la nulidad total o parcial de las Constituciones y leyes estadales, de las ordenanzas municipales y demás actos de los cuerpos deliberantes de los Estados y Municipios dictados en ejecución directa e inmediata de esta Constitución y que colidan con ella.

3. Declarar la nulidad total o parcial de los actos con rango de ley dictados por el Ejecutivo Nacional que colidan con esta Constitución.

4. Declarar la nulidad total o parcial de los actos en ejecución directa e inmediata de esta Constitución, dictados por cualquier otro órgano estatal en ejercicio del Poder Público, cuando colidan con ésta.

5. Verificar, a solicitud del Presidente o Presidenta de la República o de la Asamblea Nacional, la conformidad con esta Constitución de los tratados internacionales suscritos por la República antes de su ratificación.

6. Revisar en todo caso, aun de oficio, la constitucionalidad de los decretos que declaren estados de excepción dictados por el Presidente o Presidenta de la República.

7. Declarar la inconstitucionalidad de las omisiones* del poder legislativo municipal, estadal o nacional, cuando haya dejado de dictar las normas o medidas indispensables para garantizar el cumplimiento de esta Constitución, o las haya dictado en forma incompleta; y establecer el plazo y, de ser necesario, los lineamientos de su corrección.

8. Resolver las colisiones que existan entre diversas disposiciones legales y declarar cuál debe prevalecer.

9. Dirimir las controversias constitucionales que se susciten entre cualesquiera de los órganos del Poder Público.

10. Revisar las sentencias definitivamente firmes de amparo constitucional y de control de constitucionalidad de leyes o normas jurídicas dictadas por los tribunales de la República, en los términos establecidos por la ley orgánica respectiva.

11. Las demás que establezcan esta Constitución y la ley.

Conforme a estas previsiones, la Sala Constitucional del Tribunal Supremo de Justicia de Venezuela es, sin duda, el instrumento más poderoso diseñado para garantizar la supremacía de la Constitución y el Estado de Derecho, la cual, por supuesto, como guardián de la Constitución, también está sometida a la 
Constitución. Como tal guardián, y como sucede en cualquier Estado de Derecho, el sometimiento del Tribunal Constitucional a la Constitución es una preposición absolutamente sobreentendida y no sujeta a discusión, ya que sería inconcebible que el juez constitucional pueda violar la Constitución que esta llamado a aplicar y garantizar. Esa la pueden violar los otros poderes del Estado, pero no el guardián de la Constitución. Pero por supuesto, para garantizar que ello no ocurra, el Tribunal Constitucional debe gozar de absoluta independencia y autonomía, pues un Tribunal Constitucional sujeto a la voluntad del poder en lugar del guardián de la Constitución se convierte en el instrumento más atroz del autoritarismo. El mejor sistema de justicia constitucional, por tanto, en manos de un juez sometido al poder, es letra muerta para los individuos y es un instrumento para el fraude a la Constitución.

Lamentablemente, sin embargo, esto último es lo que ha venido ocurriendo en Venezuela en los últimos años, donde la Sala Constitucional del Tribunal Supremo, como Juez Constitucional, lejos de haber actuado en el marco de las atribuciones expresas constitucionales antes indicadas, ha venido efectuando una inconstitucional interpretación constitucional mediante la cual ha venido asumiendo y auto-atribuyéndose competencias no sólo en materia de interpretación constitucional; sino en relación con los poderes de revisión constitucional de cualquier sentencia dictada por cualquier tribunal, incluso por las otras Salas del Tribunal Supremo de Justicia; con los amplísimos poderes de avocamiento en cualquier causa; con los supuestos poderes de actuación de oficio no autorizados en la Constitución; con los poderes de solución de conflictos entre las Salas; con los poderes de control constitucional de las omisiones del Legislador; con la restricción del poder de los jueces de ejercer el control difuso de la constitucionalidad de las leyes; y con la asunción del monopolio de interpretar los casos de prevalencia en el orden interno de los tratados internacionales en materia de derechos humanos. ${ }^{13}$

En ejercicio de estas competencias y poderes, como máximo intérprete de la Constitución, al margen de la misma y mediante interpretaciones inconstitucionales, la Sala Constitucional al ejercer su facultad de interpretación del contenido y alcance de las normas constitucionales (art. 334) en muchos casos incluso sin que estas sean ambiguas, imprecisas, mal redactadas y con errores de

${ }^{13}$ Véase Allan R. Brewer-Carías, «Quis Custodiet Ipsos Custodes: De la interpretación constitucional a la inconstitucionalidad de la interpretación,» en VIII Congreso Nacional de derecho Constitucional, Perú, Fondo Editorial 2005, Colegio de Abogados de Arequipa, Arequipa, septiembre 2005, pp. 463-489; y en Revista de Derecho Público, No 105, Editorial Jurídica Venezolana, Caracas 2006, pp. 7-27. 
lenguaje, ha venido ilegítimamente modificando el texto constitucional, legitimando y soportando la estructuración progresiva de un Estado autoritario. Es decir, ha falseado el contenido de la Constitución, mediante una «mutación» ${ }^{14}$ ilegítima y fraudulenta de la misma. ${ }^{15}$

Y ello lo ha hecho el Juez Constitucional en Venezuela, lamentablemente, actuando como instrumento que ha sido del régimen autoritario, ${ }^{16}$ desde el momento mismo en el cual la Constitución fue sancionada y aprobada por el pueblo en diciembre de 1999, habiendo sucesivamente introducido múltiples modificaciones a la Constitución directamente, mediante sentencias interpretativas, o legitimando decisiones inconstitucionales de otros órganos del Estado, usurpando así el poder constituyente originario.

Estas modificaciones ilegítimas a la Constitución, por supuesto, al haber sido realizadas por el máximo guardián de la misma, que no tiene quien lo custodie, han quedado consolidadas en la vida político constitucional del país, al haber asumido la Sala Constitucional un poder constituyente derivado que no tiene y que no está regulado en el texto constitucional. La pregunta de siempre que suscita el poder incontrolado, Quis custodiet ipsos custodes, por tanto, aquí también ha adquirido todo su significado, pues no tiene respuesta. ${ }^{17} \mathrm{~A}$ continuación me referiré a algunas de las más relevantes mutaciones ilegítimas a la Constitución que considero más destacadas, ocurridas en la última década.

${ }^{14}$ Una mutación constitucional ocurre cuando se modifica el contenido de una norma constitucional de tal forma que aun cuando la misma conserva su contenido, recibe una significación diferente. Véase Salvador O. Nava Gomar, «Interpretación, mutación y reforma de la Constitución. Tres extractos» en Eduardo Ferrer Mac-Gregor (coordinador), Interpretación Constitucional, Tomo II, Ed. Porrúa, Universidad Nacional Autónoma de México, México 2005, pp. 804 ss. Véase en general sobre el tema, Konrad Hesse, «Límites a la mutación constitucional», en Escritos de derecho constitucional, Centro de Estudios Constitucionales, Madrid 1992.

${ }_{15}$ Véase Néstor Pedro Sagües, La interpretación judicial de la Constitución, Buenos Aires 2006, pp. 56-59, 80-81, 165 ss.

16 Véase Allan R. Brewer-Carías, Crónica sobre la «In» Justicia Constitucional. La Sala Constitucional y el autoritarismo en Venezuela, Caracas 2007.

17 Véase nuestros comentarios iniciales sobre esta sentencia en Allan R. Brewer-Carías, El sistema de justicia constitucional en la Constitución de 1999 (Comentarios sobre su desarrollo jurisprudencial y su explicación, a veces errada, en la Exposición de Motivos), Editorial Jurídica Venezolana, Caracas 2000. 


\section{LA ILEGÍTIMA REFORMA DE LA CONSTITUCIÓN, DESPUÉS DE SU APROBACIÓN POR EL PUEBLO, POR LA MISMA ASAMBLEA NACIONAL CONSTITUYENTE QUE LA SANCIONÓ Y SU LEGITIMACIÓN POR EL JUEZ CONSTITUCIONAL}

La primera modificación de la Constitución de 1999, que fue aprobada por el pueblo el 15 de diciembre de 1999, ocurrió una semana después, el 22 de diciembre de 1999, mediante la sanción de un Decreto de «Régimen de Transición del Poder Público» ${ }^{18}$ por la Asamblea Nacional Constituyente que había sancionado la Constitución, fundamentándose en supuestos poderes que se había auto atribuido en el artículo $1^{\circ}$ de su Estatuto de Funcionamiento, respecto de la potestad de decidir la cesación de las autoridades de los órganos del Poder Público «para hacer efectivo el proceso de transición hacia el régimen establecido en la Constitución de 1999», y en el supuesto "carácter supraconstitucional» de las normas que aprobase la Asamblea, lo que por supuesto no estaba establecido en previsión alguna del ordenamiento. Para supuestamente "permitir la vigencia inmediata de la Constitución» (art. 1), en el decreto la Asamblea procedió dictar normas constitucionales que supuestamente «desarrollan y complementan las Disposiciones Transitorias» (art. 2) de la nueva Constitución, procediendo sin atribución alguna prevista en la nueva Constitución, a eliminar el anterior Congreso con sus Senadores y Diputados, y a nombrar en su lugar una Comisión Legislativa Nacional no prevista en la Constitución; a disolver las Asambleas Legislativas de los Estados, y nombrar en su lugar unas Comisiones Legislativas Estadales tampoco previstas en la Constitución; a intervenir las Alcaldías y Consejos Municipales; a eliminar la anterior Corte Suprema de Justicia, crear las Salas del Tribunal Supremo y fijarles el número de magistrados, lo que no estaba establecido en la Constitución, y nombrarlos sin cumplir lo que la Constitución exigía; a crear una Comisión de reorganización y Funcionamiento del Poder Judicial para intervenirlo, destituyendo jueces sin debido proceso, la cual aún en 2009 convive con el Tribunal Supremo, con su complicidad; a designar a los altos funcionarios de los diversos Poderes del Estado; y a dictar un Estatuto Electoral sin poder alguno para ello.

Ninguna de estas reformas fue aprobada por el pueblo, pero impugnado el Decreto de Régimen de Transición por violar la Constitución que venía de ser aprobada por el pueblo, la Sala Constitucional del Tribunal Supremo de Justicia producto de ese régimen de transición, decidió en causa propia (la impugnación

18 Gaceta Oficial No. 36.859 de 29-12-1999 
de su propia existencia), y consideró que la Asamblea Nacional Constituyente tenía poder supraconstitucional para crear normas constitucionales sin aprobación popular, y que como consecuencia, en Venezuela existían dos regímenes constitucionales de transición: el que estaba en las disposiciones Transitorias aprobadas por el pueblo al aprobar la Constitución mediante referendo; y las aprobadas por la Asamblea Nacional Constituyente después de esa aprobación popular de la Constitución, sin que el pueblo las hubiera aprobado, pero antes de publicarla. En sentencia No 6 de fecha 27 de enero de 2000, la Sala Constitucional decidió que como el régimen de transición era un acto «publicado en la Gaceta Oficial número 36.859 del 29 de diciembre de 1999, esto es, con anterioridad a la vigencia de la Constitución de la República Bolivariana de Venezuela de 1999, no esta sujeto ni a ésta, ni a la Constitución de $1961 .{ }^{19}$ Luego en sentencia de 28 de marzo de 2000 (caso: Allan R. Brewer-Carías y otros), con motivo de declarar sin lugar la demanda de nulidad intentada contra el Estatuto Electoral del Poder Público dictado por la Asamblea Constituyente el 30 de enero de 2000, ${ }^{20}$ el Juez Constitucional ratificó su tesis de que para crear un nuevo ordenamiento jurídico y dictar una nueva Constitución que sustituyera a la de 1961, supuestamente la Asamblea Constituyente tenía varias alternativas para regular el régimen constitucional transitorio: Una, elaborar unas Disposiciones Transitorias que formaran parte de la Constitución para ser aprobada por el pueblo mediante referendo; y otra, dictar actos constituyentes aparte, de valor y rango constitucional, que originarían un régimen transitorio constitucional paralelo, no aprobado por el pueblo.

Con ello, fue el Juez Constitucional el que procedió a mutar ilegítimamente la Constitución, violando la soberanía popular, admitiendo que supuestamente, la Asamblea Nacional Constituyente podía dictar normas de rango constitucional, no aprobadas mediante referendo por el pueblo, ${ }^{21}$ con lo que se inició un largo período de transitoriedad constitucional que diez años después no ha concluido, como se evidencia de la supervivencia de la misma Comisión

${ }_{19}$ Véase en Revista de Derecho Público, No 81, (enero-marzo), Editorial Jurídica Venezolana, Caracas, 2000, pp. 81 y ss.

20 Véase en G.O. No 36.884 de 03-02-00.

${ }^{21}$ La Sala Constitucional llegó a afirmar que «Tal disposición, emanada del poder constituyente que podía lo más, cual era la transformación del Estado, lo que iba a adelantar mediante la aprobación de una nueva Constitución y del régimen de transición, claro que podía lo menos, dentro de su cometido de transformación del Estado, cual era dictar las normas que permitirían la transición entre el sistema constitucional abrogado y el nuevo, que conforme al texto constitucional de 1999, no podía de inmediato constituirse en todas sus instituciones». Véase en Revista de Derecho Público, No 81, (enero-marzo), Editorial Jurídica Venezolana, Caracas, 2000, p. 86. 
de reorganización y funcionamiento del Poder Judicial, que ejerce las funciones disciplinarias sobre los jueces, que la Constitución exige que se realice solo por jueces disciplinarios integrantes de una jurisdicción disciplinaria (art. 267). Venezuela, así tiene un régimen de transición constitucional no aprobado por el pueblo, por obra y gracia del Juez Constitucional que legitimó la usurpación de la voluntad popular.

\section{LA ILEGITÍMA MUTACIÓN EFECTUADA POR EL JUEZ CONSTITUCIONAL DE LOS EFECTOS DE LOS REFERENDOS REVOCATORIOS DE CARGOS DE ELECCIÓN POPULAR}

En Venezuela el artículo 72 de la Constitución estableció como derecho político de los ciudadano la revocatoria de mandatos de todos los cargos de elección popular, a cuyo efecto se previó que transcurrida la mitad del período para el cual fue elegido el funcionario, por iniciativa popular de un número no menor del $20 \%$ de los electores inscritos en la correspondiente circunscripción, para convocar un referendo para revocar su mandato. La Constitución dispuso que "Cuando igual o mayor número de electores o electoras que eligieron al funcionario o funcionaria hubieren votado a favor de la revocación, siempre que haya concurrido al referendo un número de electores o electoras igual o superior al $25 \%$ de los electores o electoras inscritos, se considerará revocado su mandato y se procederá de inmediato a cubrir la falta absoluta conforme a lo dispuesto en esta Constitución y en la ley.»

Es decir que los votos necesarios para que se produzca la revocatoria del mandato deben ser en un número igual o mayor de los votos de los electores que eligieron al funcionario, como lo ratificó la Sala Constitucional en varias sentencias, ${ }^{22}$ ya que de lo que se trata es de un referendo revocatorio de mandatos de elección popular y no de un referendo «ratificatorio» de tales mandatos, el cual no existe en el texto constitucional. Precisamente por ello, nada indica la Constitución para el caso de que si bien voten a favor de la revocación de un mandato un número de electores superior al número de votos que obtuvo el funcionario cuando fue electo, sin embargo, en la votación refrendaria se hu-

${ }^{22}$ Sentencia No 2750 de 21 de octubre de 2003, Caso: Carlos Enrique Herrera Mendoza, (Interpretación del artículo 72 de la Constitución (Exp. 03-1989). Sentencia No 1139 de 5 de junio de 2002 (Caso: Sergio Omar Calderón Duque y William Dávila Barrios) Véase en Revista de Derecho Público, No 89-92, Editorial Jurídica Venezolana, Caracas 2002, p. 171. Criterio seguido en la sentencia No 137 de 13-02-2003 (Caso: Freddy Lepage Scribani y otros) (Exp. 03-0287). 
biesen pronunciado por la «no revocación» un número mayor de votos. Ello podría ocurrir, pero conforme al texto de la Constitución, no tendría efecto alguno, pues la regulación constitucional lo que establece es un referendo revocatorio: basta que la votación favorable a la revocación sea igual o mayor que la que el funcionario obtuvo cuando fue electo, para que quede revocado. Y ello es así, incluso a pesar de que el Registro Electoral haya variado con el transcurso del tiempo.

Sin embargo, de manera evidentemente inconstitucional, en las Normas para regular los procesos de Referendos Revocatorios de mandatos de Elección Popular dictadas por el Consejo Nacional Electoral en 25 de septiembre de $2003^{23}$, si bien se estableció que se considera revocado el mandato «si el número de votos a favor de la revocatoria es igual o superior al número de los electores que eligieron al funcionario», se agregó la frase: «y no resulte inferior al número de electores que votaron en contra de la revocatoria» (Art. 60). Con este agregado, en una norma de rango sublegal, se restringió el derecho ciudadano a la participación política mediante la revocación de mandatos populares, al establecerse un elemento que no está en la Constitución relativo al voto por la «no revocación,» trastocándose la naturaleza «revocatoria» del referendo que regula el artículo 72 de la Constitución, y en evidente fraude a la Constitución, se lo convirtió en un referendo «ratificatorio» de mandatos de elección popular.

Lo inaudito de este fraude constitucional, es que dicha «reforma» constitucional ilegítima fue avalada por la propia Sala Constitucional del Tribunal Supremo en la sentencia No 2750 de 21 de octubre de 2003 (Caso: Carlos E. Herrera Mendoza, Interpretación del artículo 72 de la Constitución), en la cual señaló que:

Se trata de una especie de relegitimación del funcionario y en ese proceso democrático de mayorías, incluso, si en el referendo obtuviese más votos la opción de su permanencia, debería seguir en él, aunque voten en su contra el número suficiente de personas para revocarle el mandato ${ }^{24}$.

En realidad, en un referendo «revocatorio» no puede haber votos por «la permanencia» del funcionario; lo que puede haber son votos por la revocación del mandato o por la no revocación. El voto por la «no revocación» del mandato es un voto negativo (No); y un voto negativo no puede ser convertido en un voto positivo $(\mathrm{Si})$ por la permanencia del funcionario. Con esta mutación de la Constitución, la Sala Constitucional ha cambiado la naturaleza del referendo re-

\footnotetext{
${ }^{23}$ Resolución No 030925-465 de 25-09-2003.

${ }^{24}$ Exp. 03-1989.
} 
vocatorio, ratificando el trastrocamiento de la naturaleza de la revocación del mandato, convirtiéndola en un mandato para "relegitimar» o para "ratificar» mandatos de elección popular, cuando ello no sólo no fue la intención del constituyente, sino que no puede derivarse del texto del artículo 72 de la Constitución. Lo único que la Constitución regula es la revocación de mandatos, y para ello, lo único que exige en materia de votación es que un número «igual o mayor de electores que eligieron al funcionario hubieren votado a favor de la revocación.» Todo éste cambio de la Constitución tuvo un objeto preciso: evitar que el mandato del Presidente de República, Hugo Chávez, fuera revocado en 2004: el mismo fue electo en agosto de 2000 con 3.757 .774 votos, por lo que bastaba para que su mandato fuese revocado, que el voto a favor de la revocación superara esa cifra. Como lo anunció el Consejo Nacional Electoral el 27 de agosto de 2004, el voto a favor de la revocación del mandato del Presidente de la República en el referendo efectuado ese mismo mes y año, fue de 3.989.008, por lo que constitucionalmente su mandato había quedado revocado.

Sin embargo, ya se había cambiado ilegítimamente la Constitución, e independientemente de las denuncias de fraude que se formularon respecto del referendo revocatorio del 15 de agosto de 2004, el Consejo Nacional Electoral el mencionado día 27 de agosto de 2004, no sólo dio los datos definitivos de la votación efectuada en el referendo revocatorio, sino que acordó «ratificar» al Presidente de la República en su cargo hasta la terminación del período constitucional en enero de $2007 . .^{25}$

25 En efecto, en la página web del Consejo Nacional Electoral del día 27 de agosto de 2004, apareció la siguiente nota: «El presidente del Consejo Nacional Electoral, Francisco Carrasquero López, se dirigió al país en cadena nacional para anunciar las cifras definitivas y oficiales del evento electoral celebrado el pasado 15 de agosto, las cuales dan como ratificado en su cargo al Presidente de la República, Hugo Rafael Chávez Frías, con un total de 5 millones 800 mil 629 votos a favor de la opción «No». En la contienda electoral participaron 9 millones 815 mil 631 electores, de los cuales 3.989.008 se inclinaron por la opción «Sí» para revocar el mandato del Presidente Chávez. La totalización arrojó que la opción «No» alcanzó el 59,25\% de los votos, mientras el «Sí» logró el $40,74 \%$ del total general, y la abstención fue del 30,02\%. Vale destacar que para estos comicios el Registro Electoral se incrementó significativamente, alcanzando un universo de 14. 027.607 de electores con derecho a sufragar en el RR. Con base en la expresión de la voluntad popular, el Consejo Nacional Electoral, este viernes 27 de agosto, ratificará en la Presidencia de la República Bolivariana de Venezuela a Hugo Chávez Frías, quien culminará su período constitucional en el año 2006». Y en efecto, en acto solemne efectuado ese día, el Consejo Nacional Electoral acordó «ratificar» al Presidente de la República en su cargo, a pesar de que un número de electores mayor que los que lo eligieron hubieran votado a favor de la revocación de su mandato. Otro tanto haría la Asamblea Nacional, sin que esa figura de la ratificación estuviese prevista en norma constitucional alguna. Véase además, El Nacional, Caracas, 28-08-2004, pp. A-1 y A-2 


\section{LA ILEGÍTIMA MUTACIÓN EFECTUADA POR EL JUEZ CONSTITUCIONAL DEL RANGO SUPRA CONSTITUCIONAL DE LOS TRATADOS EN MATERIA DE DERECHOS HUMANOS}

Siguiendo una tendencia universal contemporánea, que ha permitido a los tribunales constitucionales la aplicación directa de los tratados internacionales en materia de derechos humanos para su protección, ampliando progresivamente el elenco de los mismos, en el propio texto de las Constituciones se ha venido progresivamente reconociendo en forma expresa el rango normativo de los referidos tratados, de manera que en la actualidad pueden distinguirse cuatro rangos diversos reconocidos en el derecho interno, rango supra constitucional, rango constitucional, rango supra legal o rango legal. ${ }^{26}$

En el caso de la Constitución venezolana de 1999, el artículo 23 dispuso expresamente lo siguiente:

Artículo 23. Los tratados, pactos y convenciones relativos a derechos humanos, suscritos y ratificados por Venezuela, tienen jerarquía constitucional y prevalecen en el orden interno, en la medida en que contengan normas sobre su goce y ejercicio más favorables a las establecidas en esta Constitución y en las leyes de la República, y son de aplicación inmediata y directa por los tribunales y demás órganos del Poder Público.

Esta norma, sin duda, es uno de las más importantes en materia de derechos humanos en el país, única en su concepción en América Latina, pues por una parte, le otorga a los tratados internacionales en materia de derechos humanos no sólo rango constitucional, sino rango supra constitucional, es decir, un rango superior respecto de las propias normas constitucionales, los cuales deben prevalecer sobre las mismas en caso de regulaciones más favorables a su ejercicio. Además, por otra parte, el artículo establece el principio de la aplicación inmediata y directa de dichos tratados por los tribunales y demás autoridades del país. Su inclusión en la Constitución, sin duda, fue un avance significativo en la cons-

${ }^{26}$ En relación con esta clasificación general, véase: Rodolfo E. Piza R., Derecho internacional de los derechos humanos: La Convención Americana, San José 1989; y Carlos Ayala Corao, «La jerarquía de los instrumentos internacionales sobre derechos humanos», en El nuevo derecho constitucional latinoamericano, IV Congreso venezolano de Derecho constitucional, Vol. II, Caracas 1996 y La jerarquía constitucional de los tratados sobre derechos humanos y sus consecuencias, México, 2003; Humberto Henderson, «Los tratados internacionales de derechos humanos en el orden interno: la importancia del principio pro homine», en Revista IIDH, Instituto Interamericano de Derechos Humanos, No. 39, San José 2004, pp. 71 y ss. Véase también, Allan R. Brewer-Carías, Mecanismos nacionales de protección de los derechos humanos, Instituto Internacional de Derechos Humanos, San José, 2004, pp.62 y ss. 
trucción del esquema de protección de los derechos humanos, que se aplicó por los tribunales declarando la prevalencia de las normas de Convención Americana de Derechos Humanos en relación con normas constitucionales y legales. Fue el caso, por ejemplo, del derecho a la revisión judicial de sentencias, a la apelación o derecho a la segunda instancia que en materia contencioso administrativa se excluía en la derogada Ley Orgánica de la Corte Suprema de Justicia de $1976,{ }^{27}$ respecto de la impugnación de actos administrativos ante la Jurisdicción contencioso administrativa emanados de institutos autónomos o Administraciones independientes. La Constitución de 1999 solo reguló como derecho constitucional el derecho de apelación en materia de juicios penales a favor de la persona declarada culpable (art. 40,1); por lo que en el mencionado caso de juicios contencioso administrativos, no existía una garantía constitucional expresa a la apelación, habiendo sido siempre declarada inadmisible la apelación contra las decisiones de única instancia de la Corte Primera de lo Contencioso. La aplicación del artículo 23 de la Constitución llevó finalmente a la Sala Constitucional del Tribunal Supremo, a resolver en 2000 la aplicación prevalente de la Convención Interamericana de Derechos Humanos, considerando:

«que el artículo 8, numerales 1 y 2 (literal h), de la Convención Americana sobre Derechos Humanos, forma parte del ordenamiento constitucional de Venezuela; que las disposiciones que contiene, declaratorias del derecho a recurrir del fallo, son más favorables, en lo que concierne al goce y ejercicio del citado derecho, que la prevista en el artículo 49, numeral 1, de dicha Constitución; y que son de aplicación inmediata y directa por los tribunales y demás órganos del Poder Público.» ${ }^{28}$.

${ }^{27}$ Véase los comentarios en Allan R. Brewer-Carías y Josefina Calcaño de Temeltas, Ley Orgánica de la Corte Suprema de Justicia, Editorial Jurídica Venezolana, Caracas 1978.

${ }^{28}$ Sentencia No. 87 del 13 de marzo de 2000, Caso: C.A. Electricidad del Centro (Elecentro) y otra vs. Superintendencia para la Promoción y Protección de la Libre Competencia. (Procompetencia), en Revista de Derecho Público, No. 81, Editorial Jurídica Venezolana, Caracas 2000, pp. 157. La Sala Constitucional incluso resolvió el caso estableciendo una interpretación obligatoria, que exigía la re-redacción de la Ley Orgánica, disponiendo lo siguiente: «En consecuencia, visto que el último aparte, primer párrafo, del artículo 185 de la Ley Orgánica de la Corte Suprema de Justicia, dispone lo siguiente: «Contra las decisiones que dicto dicho Tribunal en los asuntos señalados en los ordinales 1 al 4 de este artículo no se oirá recurso alguno»; visto que la citada disposición es incompatible con las contenidas en el artículo 8, numerales 1 y 2 (literal h), de la Convención Americana sobre Derechos Humanos, las cuales están provistas de jerarquía constitucional y son de aplicación preferente; visto que el segundo aparte del artículo 334 de la Constitución de la República establece lo siguiente: «En caso de incompatibilidad entre esta Constitución y una ley u otra norma jurídica, se aplicarán las disposiciones constitucionales, correspondiendo a los tribunales en cualquier causa, aun de oficio, decidir lo conducente», ésta Sala acuerda dejar sin apli- 
Sin embargo, desafortunadamente, la clara disposición constitucional del artículo 23, tres años después, fue interpretada por la Sala Constitucional del Tribunal Supremo de Justicia, en una forma abiertamente contraria a este precedente, al texto de la norma y a lo que fue la intención del constituyente. En efecto, en la sentencia No. 1.492 del 7 de julio de $2003,{ }^{29}$ al decidir una acción popular de inconstitucionalidad intentada contra varias normas del Código Penal contentivas de normas llamadas «leyes de desacato» por violación de la libertad de expresión y, en particular, de lo dispuesto en tratados y convenciones internacionales, la Sala Constitucional, resolvió que siendo la misma el máximo y último intérprete de la Constitución,

«al incorporarse las normas sustantivas sobre derechos humanos, contenidas en los Convenios, Pactos y Tratados Internacionales a la jerarquía constitucional... a la efectos del derecho interno es esta Sala Constitucional [la] que determina el contenido y alcance de las normas y principios constitucionales (artículo 335 constitucional), entre las cuales se encuentran las de los Tratados, Pactos y Convenciones suscritos y ratificados legalmente por Venezuela, relativos a derechos humanos."

En esta forma, la Sala Constitucional concluyó su decisión señalando que «es la Sala Constitucional quien determina cuáles normas sobre derechos humanos de esos tratados, pactos y convenios, prevalecen en el orden interno; al igual que cuáles derechos humanos no contemplados en los citados instrumentos internacionales tienen vigencia en Venezuela», limitando inconstitucionalmente el poder general de los jueces al ejercer el control difuso de la constitucionalidad, de poder aplicar directamente y dar prevalencia en el orden interno a las normas de la Convención Americana.

Finalmente, en sentencia No. 1.939 de 18 de diciembre de 2008 (Caso Gustavo Álvarez Arias y otros) la Sala Constitucional al declarar inejecutable una sentencia de la Corte Interamericana de Derechos Humanos, de fecha 5 de agosto de 2008, dictada en el caso de los ex-magistrados de la Corte Primera de lo Con-

cación la disposición transcrita, contenida en el último aparte, primer párrafo, del artículo 185 de la Ley Orgánica en referencia, debiendo aplicarse en su lugar, en el caso de la sentencia que se pronuncie, de ser el caso, sobre el recurso contencioso administrativo de anulación interpuesto por la parte actora ante la Corte Primera de lo Contencioso Administrativo (expediente $N^{\circ}$ 99-22167), la disposición prevista en el último aparte, segundo párrafo, del artículo 185 eiusdem, y la cual es del tenor siguiente: 'Contra las sentencias definitivas que dicte el mismo Tribunal ... podrá interponerse apelación dentro del término de cinco días, ante la Corte Suprema de Justicia (rectius: Tribunal Supremo de Justicia)'. Así se decide.» Idem p. 158

29 Véase en Revista de Derecho Público, No 93-96, Editorial Jurídica Venezolana, Caracas 2003, pp. 136 y ss. 
tencioso Administrativo (Apitz Barbera y otros ("Corte Primera de lo Contencioso Administrativo") vs. Venezuela), ha resuelto definitivamente que:

«el citado artículo 23 de la Constitución no otorga a los tratados internacionales sobre derechos humanos rango «supraconstitucional», por lo que, en caso de antinomia o contradicción entre una disposición de la Carta Fundamental y una norma de un pacto internacional, correspondería al Poder Judicial determinar cuál sería la aplicable, tomando en consideración tanto lo dispuesto en la citada norma como en la jurisprudencia de esta Sala Constitucional del Tribunal Supremo de Justicia, atendiendo al contenido de los artículos 7, 266.6, 334, 335, 336.11 eiusdem y el fallo número 1077/2000 de esta Sala.»

A los efectos de fundamentar su decisión, y rechazar la existencia de valores superiores no moldeables por el proyecto político autoritario, la Sala aclaró los siguientes conceptos:

«Sobre este tema, la sentencia de esta Sala No 1309/2001, entre otras, aclara que el derecho es una teoría normativa puesta al servicio de la política que subyace tras el proyecto axiológico de la Constitución y que la interpretación debe comprometerse, si se quiere mantener la supremacía de la Carta Fundamental cuando se ejerce la jurisdicción constitucional atribuida a los jueces, con la mejor teoría política que subyace tras el sistema que se interpreta o se integra y con la moralidad institucional que le sirve de base axiológica (interpretatio favor Constitutione). Agrega el fallo citado: «en este orden de ideas, los estándares para dirimir el conflicto entre los principios y las normas deben ser compatibles con el proyecto político de la Constitución (Estado Democrático y Social de Derecho y de Justicia) y no deben afectar la vigencia de dicho proyecto con elecciones interpretativas ideológicas que privilegien los derechos individuales a ultranza o que acojan la primacía del orden jurídico internacional sobre el derecho nacional en detrimento de la soberanía del Estado».

Concluye la sentencia que: «no puede ponerse un sistema de principios supuestamente absoluto y suprahistórico por encima de la Constitución» y que son inaceptables las teorías que pretenden limitar «so pretexto de valideces universales, la soberanía y la autodeterminación nacional».

En el mismo sentido, la sentencia de esta Sala No 1265/2008 estableció que en caso de evidenciarse una contradicción entre la Constitución y una convención o tratado internacional, «deben prevalecer las normas constitucionales que privilegien el interés general y el bien común, debiendo aplicarse las disposiciones que privilegien los intereses colectivos...(...) sobre los intereses particulares.... ${ }^{30}$

${ }^{30}$ Véase en http://www.tsj.gov.ve/decisiones/scon/Diciembre/1939-181208-2008-081572.html 
En esta forma, la Sala Constitucional en el Venezuela ha dispuesto una ilegítima mutación constitucional, reformando el artículo 23 de la Constitución al eliminar el carácter supranacional de la Convención Americana de Derechos Humanos en los casos en los cuales contenga previsiones más favorables al goce y ejercicio de derechos humanos respecto de las que están previstas en la propia Constitución.

Debe advertirse, por otra parte, que tan se trata de una reforma constitucional ilegítima, que esa fue una de las propuestas de reforma que se formularon por el «Consejo Presidencial para la Reforma de la Constitución,» designado por el Presidente de la República, ${ }^{31}$ en informe de junio de $2007,{ }^{32}$ en el cual, en relación con el artículo 23 de la Constitución, lo que se buscaba era eliminar totalmente la jerarquía constitucional de las previsiones de los tratados internacionales de derechos humanos y su prevalencia sobre el orden interno, proponiéndose la formulación de la norma sólo en el sentido de que: «los tratados, pactos y convenciones relativos a derechos humanos, suscritos y ratificados por Venezuela, mientras se mantenga vigentes, forma parte del orden interno, y son de aplicación inmediata y directa por los órganos del Poder Público».

Esa propuesta de reforma constitucional que afortunadamente no llegó a cristalizar, era un duro golpe al principio de la progresividad en la protección de los derechos que se recoge en el artículo 19 de la Constitución, que no permite regresiones en la protección de los mismos. ${ }^{33}$ Sin embargo, lo que no pudo hacer el régimen autoritario mediante una reforma constitucional, la cual al final fue rechazada por el pueblo, lo hizo la Sala Constitucional del Tribunal Supremo en su larga carrera al servicio del autoritarismo. ${ }^{34}$

31 Véase Decreto No. 5138 de 17-01-2007, Gaceta Oficial No 38.607 de 18-01-2007

32 El documento circuló en junio de 2007 con el título Consejo Presidencial para la Reforma de la Constitución de la República Bolivariana de Venezuela, «Modificaciones propuestas». El texto completo fue publicado como Proyecto de Reforma Constitucional. Versión atribuida al Consejo Presidencial para la reforma de la Constitución de la república Bolivariana de Venezuela, Editorial Atenea, Caracas 01 de julio de 2007, 146 pp.

33 Véase esta proyectada reforma constitucional Allan R. Brewer-Carías, Hacia la consolidación de un Estado Socialista, Centralizado, Policial y Militarista. Comentarios sobre el sentido y alcance de las propuestas de reforma constitucional 2007, Colección Textos Legislativos, No. 42, Editorial Jurídica Venezolana, Caracas 2007, pp. 122 ss.

34 Véase entre otros aspectos, los contenidos en el libro Allan R. Brewer-Carías, Crónica sobre la "In" Justicia Constitucional. La Sala Constitucional y el autoritarismo en Venezuela, Colección Instituto de Derecho Público, Universidad Central de Venezuela, No. 2, Caracas 2007. 


\section{LA ILEGÍTIMA MUTACIÓN EFECTUADA POR EL JUEZ CONSTITUCIONAL DEL PRINCIPIO DE LA ALTERNABILIDAD REPUBLICANA, LA ENMIENDA CONSTITUCIONAL PARA ESTABLECER LA REELECCIÓN INMEDIATA Y CONTINUA DE LOS FUNCIONARIOS ELECTOS, Y LA MODIFICACIÓN DE LOS EFECTOS DEL RECHAZO POPULAR A REFORMAS CONSTITUCIONALES}

El artículo 6 de la Constitución establece los principios fundamentales del gobierno republicano, en una cláusula de las denominadas "pétreas,», en la cual se dispone que

Artículo 6. El gobierno de la República Bolivariana de Venezuela y de las entidades políticas que la componen es y será siempre democrático, participativo, electivo, descentralizado, alternativo, responsable, pluralista y de mandatos revocables.

Entre estos principios fundamentales del sistema constitucional, que por tanto, no pueden ser modificados ni mediante los procedimientos de reforma constitucional ni de enmienda constitucional, sino sólo mediante la convocatoria de una Asamblea Nacional Constituyente, está el principio de que el gobierno además de ser «democrático» y «electivo» debe ser siempre «alternativo,» y es por tanto, inmodificable. «El gobierno es y será siempre ... alternativo», dice la norma, ello que implica que ello nunca podría ser alterado. Esa fue la voluntad del pueblo al aprobar la Constitución.

El principio fue incorporado por primera vez en la historia constitucional como reacción al continuismo en el poder y entre otros aspectos, con base en la propia «doctrina de Simón Bolívar» en la cual la República se fundamenta conforme al artículo 1 de la Constitución, al expresar en uno de sus escritos que:

«..nada es tan peligroso como dejar permanecer largo tiempo en un mismo ciudadano el poder. El pueblo se acostumbra a obedecerle y él se acostumbra a mandarlo. ... nuestros ciudadanos deben temer con sobrada justicia que el mismo Magistrado, que los ha mandado mucho tiempo, los mande perpetuamente». ${ }^{35}$

De acuerdo con esta doctrina, que como «bolivariana» forma parte de los valores de la propia constitución (artículo 1), en el constitucionalismo venezolano

35 Véase Simón Bolívar, «Discurso de Angostura» (1819), en Escritos Fundamentales, Caracas, 1982 
la palabra usada de gobierno «alternativo» o de la «alternabilidad» en el poder, en relación con los cargos públicos siempre ha tenido el significado de que las personas deben turnarse sucesivamente en los mismos o que los cargos deben desempeñarse por turnos (Diccionario de la Real Academia Española). Como lo señaló la Sala Electoral del Tribunal Supremo de Justicia en sentencia No. 51 de 18-3-2002, alternabilidad significa «el ejercicio sucesivo de un cargo por personas distintas, pertenezcan o no a un mismo partido.»

Este principio de la alternabilidad, como principio fundamental, se concibió históricamente para enfrentar las ansias de perpetuación en el poder, es decir, el continuismo, y evitar las ventajas en los procesos electorales de quienes ocupan cargos y a la vez puedan ser candidatos para ocupar los mismos cargos. El principio de «gobierno alternativo,» por tanto, no es equivalente al de «gobierno electivo.» La elección es una cosa, y la necesidad de que las personas se turnen en los cargos es otra, y por ello el principio se ha reflejado siempre en el establecimiento de límites a la reelección de los funcionarios electos, lo que por lo demás es propio de los sistemas presidenciales de gobierno. Así sucedió en las Constituciones de 1830, 1858, 1864, 1874, 1881, 1891, 1893, 1901, 1904, 1909, 1936, 1845 y 1947 en las cuales se estableció, por ejemplo, la prohibición de la reelección del Presidente de la República para el período constitucional inmediato. $^{36}$

Esta prohibición, en cambio, respecto del Presidente de la República, en el período democrático iniciado en 1958 fue más amplia y se extendió en la Constitución de 1961 a los dos períodos siguientes (10 años). La flexibilización del principio se produjo en la Constitución de 1999, en la cual se permitió la posibilidad de reelección presidencial de inmediato y por una sola vez, para un nuevo período. Conforme a ella, el Presidente de la República fue reelecto en 2006.

La alternabilidad del gobierno, por tanto, es un principio del constitucionalismo que se opone al continuismo o a la permanencia en el poder por una misma persona, por lo que toda previsión que permita que esto pudiera ocurrir, sería contraria al mismo. El principio, por tanto, no se puede confundir con el principio «electivo» del gobierno o con el más general principio «democrático» que el mismo artículo 6 de la Constitución establece. Una cosa es poder elegir a los gobernantes, y otra cosa es el principio de alternabilidad que impide poder escoger al mismo gobernante ilimitadamente.

36 En la historia constitucional del país, en realidad, la prohibición de la reelección presidencial inmediata solamente dejó de establecerse en las Constituciones de los gobiernos autoritarios: en la efímera Constitución de 1857; en las Constituciones de Juan Vicente Gómez de 1914, 1922, 1925, 1928, 1929 y 1931, y en la Constitución de Marcos Pérez Jiménez de 1953. 
Es contrario a la Constitución, por tanto, interpretar, como lo ha hecho la Sala Constitucional en su sentencia No. 53 de 3 de febrero de 2009, que el principio de la alternabilidad «lo que exige es que el pueblo como titular de la soberanía tenga la posibilidad periódica de escoger sus mandatarios o representantes», confundiendo "gobierno alternativo» con "gobierno electivo.» Por ello es falso lo que ha afirmado la Sala Constitucional en el sentido de que «sólo se infringiría el mismo si se impide esta posibilidad al evitar o no realizar las elecciones». Con su sentencia, la Sala Constitucional de nuevo lo que ha hecho es mutar ilegítimamente el texto de la Constitución, y al contrario de lo que ha afirmado, la eliminación de la causal de inelegibilidad para el ejercicio de cargos públicos derivada de su ejercicio previo por parte de cualquier ciudadano, sí trastoca el principio de alternabilidad en el ejercicio del poder.

Lo expuesto por la Sala Constitucional se refiere al principio de gobierno «electivo» que en los términos del mismo artículo 6 de la Constitución, es el que implica que «el electorado, como actor fundamental del proceso democrático, acuda a procesos comiciales periódicamente en los que compitan, en igualdad de condiciones, las diversas opciones políticas que integran el cuerpo social;» pero no al principio de gobierno «alternativo» que implica que no se pueda elegir indefinidamente una misma persona para el mismo cargo, así haya hecho un «buen gobierno.» El principio de la alternabilidad, para evitar el continuismo en el poder, precisamente implica la limitación que el pueblo, como poder constituyente originario, se ha impuesto a si mismo, en cuanto a que supuestamente pueda tener la «oportunidad de decidir entre recompensar a quienes estime como sus mejores gobernantes, o bien renovar completamente las estructuras del poder cuando su desempeño haya sido pobre.» Esta supuesta "oportunidad,» por el principio de la alternabilidad en la Constitución, pudo ejercerse antes de 1999, sólo después de que, en sus casos, transcurrieron uno o dos períodos constitucionales siguientes al ejercicio de la Presidencia por quien pretendiera de nuevo optar a dicho cargo, y en la Constitución de 1999 sólo ocurrió en 2006, por una sola vez para un período inmediato, mediante la reelección ya efectuada del Presidente Chávez. Pero establecer dicha «oportunidad» como reelección continua, sin límite, sería contrario al principio de la alternabilidad.

Por tanto, al contrario de lo decidido por la Sala Constitucional, la posibilidad de reelección continua sí altera el principio fundamental del gobierno «alternativo", que es uno de los valores democráticos que informan nuestro ordenamiento jurídico. Dicho principio, que se altera si se establece la posibilidad de elección continua de cargos electivos y que es distinto del principio del gobierno «electivo», al tener una formulación pétrea en el artículo 6 de la Constitución (es y será siempre) no puede ser objeto de modificación constitucional alguna, y 
en el supuesto negado de que pudiera ser modificado, ello no se podría realizarse ni por los procedimientos de Enmienda ni de Reforma Constitucional sino sólo mediante la convocatoria de una Asamblea Nacional Constituyente.

La Sala Constitucional, con su sentencia No. 53 de de febrero de 2009, en realidad ha mutado la Constitución a través de una interpretación, modificando ilegítimamente el sentido del principio del gobierno 'alternativo' que los venezolanos dispusieron que siempre debe regir sus gobiernos, obviando la prohibición constitucional de que se pueda consultar en un mismo período constitucional, la voluntad popular sobre modificaciones constitucionales que ya el pueblo ha rechazado.

Con esta sentencia, en todo caso, lo que hizo la Sala Constitucional fue allanar el camino para que se realizara el referendo aprobatorio que fue convocado para el 15 de febrero de 2009 a los efectos de votar por la aprobación o rechazo de un proyecto de «Enmienda Constitucional» relativa a los artículos 160, 162, 174, 192 y 230 de la Constitución, para establecer en Venezuela el principio de la reelección continua de cargos electivos, contrariando el principio constitucional de la alternabilidad republicana (art. 6).

Además, en la sentencia, también se realizó otra ilegítima mutación adicional a la Constitución, al allanarse el camino para la violación de la prohibición constitucional de realizar una consulta popular sobre modificaciones a la Constitución que ya habían sido rechazadas por el pueblo en un mismo período constitucional (art. 345).

En efecto, en los procedimientos de reforma constitucional la Constitución establece una prohibición expresa de que se pueda presentar a la Asamblea Nacional otra iniciativa de «reforma constitucional» rechazada por el pueblo en el mismo período constitucional. Nada se establece, en cambio en cuanto a los efectos del rechazo de la «Enmienda Constitucional», ni si rechazada una «reforma constitucional» por el pueblo la misma modificación se puede presentar de seguidas mediante el procedimiento de "enmienda constitucional.» Fue precisamente en este marco constitucional, en el cual la Asamblea Nacional en enero de 2009 tomó la iniciativa y aprobó un proyecto de Enmienda Constitucional, que si bien inicialmente sólo perseguía modificar el artículo 230 de la Constitución sobre reelección del Presidente, luego se extendió a los artículos 160, 162, 174 y 192 de la Constitución sobre reelección de otros cargos electivos, en los cuales se establecen límites para la reelección, a los efectos de eliminar dichos límites.

Sin embargo, en 2 de diciembre de 2007 el pueblo ya había rechazado con su voto popular en el referendo convocado para aprobar una «Reforma Constitucional» formulada a iniciativa del Presidente de la República ante la Asamblea 
Nacional, la propuesta de reforma para establecer, entre otros aspectos, la posibilidad de la reelección continua del Presidente de la República mediante la eliminación de la limitación constitucional a la reelección, antes indicada. Siendo la manifestación de la voluntad popular el rechazar la propuesta de modificación constitucional, conforme al artículo 345 de la Constitución no se podía someter de nuevo a consulta popular, de nuevo, la misma reforma en el mismo período constitucional.

Este fue otro de los temas que se había solicitado a la sala Constitucional que interpretara. Sin embargo, sobre este primer punto respecto de si la prohibición contenida en el artículo 345 de la Constitución en el sentido de que la iniciativa de reforma constitucional que no fuese aprobada no podía presentarse de nuevo en un mismo período constitucional a la Asamblea Nacional, la Sala Constitucional, confundiendo el sentido de la norma, sostuvo que la misma no estaba destinada a regular los efectos de la manifestación de rechazo popular de la modificación propuesta, sino que sostuvo que la norma estaba sólo dirigida a regular a la Asamblea Nacional, en el sentido de que lo que no podría era exigírsele que debatiera una reforma constitucional una vez que ya la ha debatido en el mismo período constitucional y había sido rechazada por el pueblo. La Sala olvidó que la norma constitucional a lo que está dirigida es a regular las consultas a la voluntad popular en materia de modificación de la Constitución y sus efectos, y no los efectos de los debates en la Asamblea Nacional.

En efecto, la prohibición constitucional de volver a someter a consulta una reforma rechazada, en realidad está dirigida a regular los efectos de la voluntad popular expresada mediante referendo, en el sentido de que no se puede consultar al pueblo de nuevo la misma modificación constitucional que el pueblo ya ha rechazado en un mismo período constitucional.

Lo importante de la prohibición establecida en un Título de la Constitución relativo a la «Reforma Constitucional,» que en Venezuela sólo puede realizarse con la participación del pueblo, es que la misma se refiere precisamente a los efectos de la expresión de la voluntad popular que es manifestación del poder constituyente originario, y no a los efectos del debate que pueda haber habido en la Asamblea Nacional en la materia, que no es poder constituyente, ni siquiera derivado, ya que no puede haber modificación constitucional alguna sin aprobación popular.

La decisión de la Sala Constitucional es una nueva burla a la Constitución al ignorar la prohibición de sucesivas consultas populares, basándose en dos artilugios que se utilizaron en este caso de la Enmienda constitucional de febrero de 2009: primero, el utilizado por la Asamblea Nacional, en su iniciativa de Enmienda, al extenderla a otros artículos constitucionales además del 230, para tra- 
tar de diferenciar la Enmienda Constitucional de 2009 de la rechazada Reforma Constitucional de 2007; y segundo, el utilizado por la Sala Constitucional al considerar que la prohibición constitucional de consultar al pueblo sobre reformas rechazadas es sólo formal respecto de las discusiones en la Asamblea Nacional, ignorando su propósito esencial de respetar la voluntad popular una vez que esta se ha expresado en forma negativa respecto de una modificación de la Constitución.

Esa voluntad hay que respetarla, que es lo que persigue la Constitución, por lo que una vez que el pueblo se ha manifestado rechazando una modificación al texto constitucional no se lo puede estar convocando sucesivamente sin límites en el mismo período constitucional para volver a pronunciarse sobre lo mismo.

\section{LA ILEGÍTIMA MUTACIÓN CONSTITUCIONAL EFECTUADA POR EL JUEZ CONSTITUCIONAL RESPECTO DE LA PROHIBICIÓN DEL FINANCIAMIENTO PÚBLICO A LAS ACTIVIDADES DE LOS PARTIDOS POLÍTICOS}

El artículo 67 de la Constitución de 1999 expresamente prohibió «el financiamiento de las asociaciones con fines políticos con fondos provenientes del Estado", al establecer enfáticamente que el mismo «no se permitirá», ${ }^{37}$ cambiando así, radicalmente, el régimen de financiamiento público a los partidos políticos que se había previsto en el artículo 230 de la Ley Orgánica del Sufragio y Participación Política de 1998. En dicha Ley se había buscado establecer un mayor equilibrio y equidad para la participación de los partidos en la vida democrática y en especial en las campañas electorales, tratando de mitigar los desequilibrios y perversiones que podían producirse con el solo financiamiento privado a los partidos, con el riesgo de presencia de «narcofinanciamiento» por ejemplo, y el eventual financiamiento público indirecto, irregular y corrupto, sólo para los partidos de gobierno, ${ }^{38}$ que en un sistema donde no existe control fiscal ni parlamentario del ejercicio del poder, puede magnificarse. Con la prohibición

37 Véase sobre la versión inicial de esta norma y sobre nuestra propuesta para su redacción en Allan R. Brewer-Carías Debate Constituyente (Aportes a la Asamblea Nacional Constituyente), Tomo II (9 septiembre - 17 octubre 1999). Fundación de Derecho Público - Editorial Jurídica Venezolana. Caracas, 1999. P.129 en'4e

38 Véase en general sobre el tema, Allan R. Brewer-Carías, "Consideraciones sobre el financiamiento de los partidos políticos en Venezuela» en Financiamiento y democratización interna de partidos politicos. Memoria del IV Curso Anual Interamericano de Elecciones, San José, Costa Rica, 1991 , pp. 121 a $139 .$. 
constitucional, al derogarse este artículo de la Ley Orgánica, quedó derogado con el régimen de financiamiento público a los partidos políticos, abandonándose la tendencia inversa que predomina en el derecho comparado.

Esta prohibición constitucional expresa sobre el financiamiento público de los partidos políticos, fue uno de los temas a los que se refirió la reforma constitucional que a iniciativa del Presidente de la República, ${ }^{39}$ se pretendió aprobar durante el año 2007, con la cual expresamente se buscó modificar la mencionada prohibición constitucional del artículo 67, previéndose en la norma, al contrario, que «el Estado podrá financiar las actividades electorales», pero sin indicarse si se trata de un financiamiento a los partidos políticos en general. Como es sabido, la antes mencionada propuesta de Reforma Constitucional de 2007, fue rechazada por voluntad popular expresada abrumadoramente contra su aprobación en el referendo del 2 de diciembre de $2007,{ }^{40}$ con lo que el régimen de financiamiento a los partidos políticos, a su funcionamiento interno y a sus actividades electorales continuó prohibida en la Constitución.

Sin embargo, a pesar de dicha prohibición constitucional y del rechazo popular a modificarla, la Sala Constitucional del Tribunal Supremo de Justicia, actuando como Jurisdicción Constitucional, en sentencia No. 780 de 8 de mayo de 2008 (Exp. $\mathrm{n}^{\circ}$ 06-0785), mediante una interpretación constitucional vinculante, ha mutado la Constitución, sustituyéndose a la voluntad popular y al poder constituyente originario, disponiendo que «en lo que respecta al alcance de la prohibición de financiamiento público de asociaciones políticas» contenida en la mencionada norma, la misma:

«se circunscribe a la imposibilidad de aportar fondos a los gastos corrientes e internos de las distintas formas de asociaciones políticas, pero ...dicha limitación, no resulta extensiva a la campaña electoral, como etapa fundamental del proceso electoral».

Es decir, la Sala Constitucional, ante una norma tan clara e igualmente tan criticable como la contenida en el artículo 67 de la Constitución, cuya reforma se había intentado hacer en 2007 pero sin lograrse por ser rechazada por la vo-

39 Véase el documento Proyecto de Exposición de Motivos para la Reforma Constitucional, Presidencia de la República, Proyecto Reforma Constitucional. Propuesta del presidente Hugo Chávez Agosto 2007; y la publicación: Proyecto de Reforma Constitucional. Elaborado por el ciudadano Presidente de la República Bolivariana de Venezuela, Hugo Chávez Frías Editorial Atenea, Caracas agosto 2007, p. 19

40 Véase Allan R. Brewer-Carías, «La proyectada reforma constitucional de 2007», rechazada por el poder constituyente originario", en Anuario de Derecho Público 2007, Universidad Monteavila, Caracas 2008. 
luntad popular, en esta sentencia ni más ni menos, se ha erigido en poder constituyente, sustituyendo al pueblo, y ha dispuesto la reforma de la norma, vía su interpretación, en el mismo sentido que se pretendía en la rechazada reforma constitucional, disponiendo en definitiva, que la prohibición constitucional «no limita que en el marco del proceso electoral y como gasto inherente a una fase esencial del mismo, el Estado destine fondos con el objeto de financiar el desarrollo de las campañas electorales, de los partidos y asociaciones políticas,» es decir, lo contrario de lo que dispone la Constitución.

Es evidente que siendo el financiamiento de las campañas electorales la motivación fundamental del financiamiento de los partidos políticos, pues los mismos tienen por objeto conducir a la ciudadanía en las opciones democráticas que necesariamente desembocan en elecciones, la Ley Orgánica del Sufragio y participación Política había dispuesto el financiamiento de los paridos políticos; y ello fue lo que sin embargo, se eliminó expresamente en la Constitución de 1999. En la Constitución de 1999, sin embargo, en su clara concepción anti partidos entre otras normas dispuso precisamente la prohibición constitucional del financiamiento público a los partidos políticos (art. 67) lo cual lamentablemente ha provocado la posibilidad no sólo al financiamiento privado ilegítimo (narcotráfico, comisiones de partidos), sino al financiamiento público irregular. ${ }^{41} \mathrm{Y}$ eso fue precisamente lo que se quiso corregir, de nuevo, con la proyectada Reforma Constitucional de 2007, la cual, sin embargo, fue rechazada por el pueblo.

Pero la Sala Constitucional, sin límite alguno, se sustituyó al pueblo y asumió el rol de poder constituyente originario, disponiendo que lo que la Constitución prohíbe cuando establece en el artículo 67 que no se permite «el financiamiento de las asociaciones con fines políticos con fondos provenientes del Estado», es sólo una prohibición al financiamiento por el Estado de «los gastos corrientes e internos de las distintas formas de asociaciones políticas», pero no de la «campaña electoral, como etapa fundamental del proceso electoral».

Es decir, el Juez Constitucional, simplemente, dispuso que la Constitución no dice lo que dice, sino todo lo contrario; que cuando dice que no se permite «el financiamiento de las asociaciones con fines políticos con fondos provenientes del Estado», no es eso lo que establece, sino lo que prohíbe es solamente «el financiamiento de los gastos corrientes e internos de las asociaciones con fines políticos con fondos provenientes del Estado»; y que los gastos de las

41 Véase en Allan R. Brewer-Carías, «Regulación jurídica de los partidos políticos en Venezuela» en Estudios sobre el Estado Constitucional (2005-2006), Cuadernos de la Cátedra Fundacional Allan R. Brewer Carías de Derecho Público, Universidad Católica del Táchira, No 9, Editorial Jurídica Venezolana. Caracas, 2007, pp. 655-686 
campañas electorales de dichas asociaciones con fines políticas, en cambio, sí pueden ser financiadas con fondos provenientes del Estado.

Y para llegar a esta conclusión, en una sentencia innecesariamente atiborrada de citas de autores sobre las técnicas de interpretación y la noción de democracia, y sobre las bondades del financiamiento público de las campañas electorales de los partidos políticos, concluyó en la mencionada distinción, de que una cosa es que el Estado financie «los gastos corrientes e internos» de los partidos políticos y otra cosa es que financie «sus campañas electorales,» deduciendo sin fundamento alguno que lo que la Constitución prohíbe es lo primero y no lo segundo.

Se trata de una conclusión absurda, que contra toda lógica democrática, se deriva de una premisa falsa, y es que en sistemas democráticos supuestamente podría ocurrir que el Estado financie los gastos corrientes e internos de los partidos. Ello no se concibe en las democracias, por lo que no requiere de prohibición alguna. En democracias lo que se financia es el funcionamiento de los partidos pero con miras siempre a las campañas electorales, al punto de que este se suspende si los mismos no llegan a obtener un determinado porcentaje de votación en las elecciones.

Puede ser muy loable la intención del Juez Constitucional de permitir el financiamiento de las campañas electorales de los partidos políticos con fondos provenientes del Estado, pero habiendo sido ello prohibido expresamente por la Constitución ${ }^{42}$ (ya que no tiene lógica afirmar que lo que se prohíbe es lo que nunca se ha permitido: el financiamiento de los gastos corrientes e internos de los partidos), sólo reformándola es que se podría lograr lo contrario. Y ello fue lo que en este caso hizo el Juez Constitucional en Venezuela: reformar la Constitución, usurpando el poder constituyente originario que es del pueblo e, incluso contra su propia voluntad expresada cinco meses antes al rechazar precisamente esa reforma constitucional en igual sentido, estableció la posibilidad de financiar las campañas electorales de los partidos políticos.

\section{APRECIACIÓN FINAL}

Las anteriores son sólo algunas de las ilegítimas mutaciones a la Constitución efectuadas por la Sala Constitucional del Tribunal Supremo de Justicia, la ma-

${ }^{42}$ Por ello fue, incluso, que entre otros aspectos salvamos nuestro voto en relación con dicha norma. Véase Allan R. Brewer-Carías, Debate Constituyente (Aportes a la Asamblea Nacional Constituyente), Tomo III (18 octubre-30 noviembre 1999). Fundación de Derecho Público Editorial Jurídica Venezolana. Caracas, 1999. pp. 239, 259 
yoría al decidir recursos autónomos de interpretación abstracta de la Constitución, creado por la misma. Dicho instrumento, en manos de un Juez Constitucional autónomo e independiente, sin duda que podría ser un eficaz medio para adaptar las normas constitucionales a los cambios operados en el orden constitucional de un país en un momento determinado.

Sin embargo, un recurso de esa naturaleza en manos de un Juez Constitucional totalmente dependiente del Poder Ejecutivo, en un régimen autoritario como el que se ha estructurado en Venezuela en los últimos 10 años, resolviendo en particular las peticiones interesadas que le formule el propio Poder Ejecutivo a través del Procurador General de la República, es un instrumento de mutación ilegítima de la Constitución, para cambiarla y ajustarla a la voluntad del poder y afianzar el autoritarismo. ${ }^{43}$ Eso es lo que ha ocurrido en Venezuela, luego de que el Tribunal Supremo de Justicia fue intervenido políticamente, al distorsionarse las normas constitucionales destinadas a asegurar su nombramiento que exigían su propuesta por la sociedad civil, y las destinadas a su remoción sólo en casos excepcionales.

En efecto, en cuanto a la selección de los Magistrados del Tribunal Supremo de Justicia, la Constitución de 1999 creó un novedoso sistema, mediante el establecimiento de un Comité de Postulaciones Judiciales (art. 270), que debería estar integrado por representantes de los diferentes sectores de la sociedad. Ello, sin embargo, no se ha garantizado en los 10 años de vigencia de la Constitución: No se garantizó en la designación de Magistrados en 1999 por la Asamblea Nacional Constituyente; ni se garantizó en 2001, con la nueva la designación de Magistrados mediante una «Ley Especial» que convirtió dicho Comité en una comisión parlamentaria ampliada. Luego, después de años de transitoriedad constitucional, tampoco se garantizó en la Ley Orgánica del Tribunal Supremo de Justicia de 2004, la cual en lugar de regular dicho Comité, lo que estableció fue una Comisión parlamentaria ampliada, totalmente controlada por la mayoría oficialista del Parlamento, burlando la disposición constitucional ${ }^{44}$. Con dicha

${ }^{43}$ Véase Allan R. Brewer-Carías, «Le recours d'interprétation abstrait de la Constitution au Vénézuéla», en Le renouveau du droit constitutionnel, Mélanges en l'honneur de Louis Favoreu, Dalloz, Paris, 2007, pp. 61-70

${ }_{44}$ Véase los comentarios en Allan R. Brewer-Carías, Ley Orgánica del Tribunal Supremo de Justicia, Editorial Jurídica Venezolana, Caracas 200, pp. 32 ss. El asalto al Tribunal Supremo de Justicia se inició antes con el nombramiento «transitorio», en 1999, por la Asamblea Nacional Constituyente, de los nuevos Magistrados del Tribunal Supremo de Justicia sin cumplirse los requisitos constitucionales ni asegurarse la participación de la sociedad civil en los nombramientos. Las previsiones constitucionales sobre condiciones para ser magistrado y los procedimientos para su designación con participación de los sectores de la sociedad, se continuaron vio- 
reforma, además, se aumentó el número de Magistrados de 20 a 32, los cuales fueron elegidos por la Asamblea Nacional en un procedimiento que estuvo enteramente controlado por el Presidente de la República, lo que incluso fue anunciado públicamente en víspera de los nombramientos, por el entonces Presidente de la Comisión parlamentaria encargada de escoger los candidatos a Magistrado. ${ }^{45}$

Por otra parte, en cuanto a la estabilidad de los Magistrados del Tribunal Supremo de Justicia, el artículo 265 de la Constitución dispuso que los mismos sólo podían ser removidos por la Asamblea Nacional mediante una mayoría calificada de las dos terceras partes de sus integrantes, previa audiencia concedida al interesado, en caso de faltas graves calificadas por el Poder Ciudadano. Con esta sola disposición, sin embargo, podía decirse que la autonomía e independencia de los Magistrados quedaba cuestionada pues permitía una inconveniente e inaceptable injerencia de la instancia política del Poder en relación con la administración de Justicia, y con ella, efectivamente, la Asamblea Nacional comenzó a ejercer un control político directo sobre los Magistrados del Tribunal Supremo, los cuales permanentemente han sabido que en cualquier momento pueden ser investigados y removidos. Pero en la norma constitucional al menos había la garantía con la exigencia de una mayoría calificada para la votación, lo cual sin embargo fue absurdamente eliminada, al preverse otra modalidad de remoción, llamada de "revocación del acto administrativo de nombramiento» con el voto de la mayoría absoluta de los diputados, lo que se estableció en evidente fraude a la Constitución, en la Ley Orgánica del Tribunal Supremo de Jus-

lando por la Asamblea Nacional al hacer las primeras designaciones en 2002 conforme a una «Ley especial» sancionada para efectuarlas transitoriamente, con contenido completamente al margen de las exigencias constitucionales

45 El diputado Pedro Carreño, quien un tiempo después fue designado Ministro del Interior y de Justicia, afirmó lo siguiente: «Si bien los diputados tenemos la potestad de esta escogencia, el Presidente de la República fue consultado y su opinión fue tenida muy en cuenta.» Agregó: «Vamos a estar claros, nosotros no nos vamos a meter autogoles. En la lista había gente de la oposición que cumple con todos los requisitos. La oposición hubiera podido usarlos para llegar a un acuerdo en las últimas sesiones, pero no quisieron. Así que nosotros no lo vamos a hacer por ellos. En el grupo de los postulados no hay nadie que vaya a actuar contra nosotros y, así sea en una sesión de 10 horas, lo aprobaremos.» Véase en El Nacional, Caracas, 13-12-2004. Con razón, la Comisión Interamericana de Derechos Humanos indicó en su Informe a la Asamblea General de la OEA correspondiente a 2004 que «estas normas de la Ley Orgánica del Tribunal Supremo de Justicia habrían facilitado que el Poder Ejecutivo manipulara el proceso de elección de magistrados llevado a cabo durante 2004». Comisión Interamericana de Derechos Humanos, Informe sobre Venezuela 2004, párrafo 180. 
ticia en $2004 .{ }^{46}$ Esta inconstitucional previsión legal, incluso, se buscó constitucionalizar con la rechazada reforma constitucional de $2007 .{ }^{47}$

En esta forma, el Tribunal Supremo de Justicia de Venezuela, y dentro del mismo, su Sala Constitucional, se ha configurado como un cuerpo altamente politizado ${ }^{48}$, lamentablemente sujeto a la voluntad del Presidente de la República, lo que en la práctica ha significado la eliminación de toda la autonomía del Poder Judicial. Con ello, el propio postulado de la separación de los poderes, como piedra angular del Estado de Derecho y de la vigencia de las instituciones democráticas, ha sido eliminando desapareciendo toda posibilidad de control judicial efectivo del poder por parte de los ciudadanos. El propio Presidente de la República incluso, llegó a decir en 2007 que para poder dictar sentencias, el Tribunal Supremo debía consultarlo previamente. ${ }^{49}$ Con todo esto, el Poder Judicial ha pospuesto su función fundamental de servir de instrumento de control de las actividades de los otros órganos del Estado para asegurar su sometimiento a la ley, habiendo materialmente desaparecido el derecho ciudadano a la tutela judicial efectiva y al controlar del poder. En esa situación, por tanto, es difícil ha-

46 Se estableció, en efecto, la posibilidad de la «revocación del acto administrativo de nombramiento los Magistrados» por mayoría para burlar la exigencia de la mayoría calificada prevista para la «remoción». Véase los comentarios en Allan R. Brewer-Carías, Ley Orgánica del Tribunal Supremo de Justicia, Editorial Jurídica Venezolana, Caracas 200, pp. 41 ss.

47 Véase Allan R. Brewer-Carías, Hacia la consolidación de un Estado Socialista, Centralista, Policial y Militarista. Comentarios sobre el alcance y sentido de las propuestas de reforma constitucional 2007, Editorial Jurídica Venezolana, Caracas 2007, pp. 114 ss.; La Reforma Constitucional de 2007 (Inconstitucionalmente sancionada por la Asamblea nacional el 2 de noviembre de 2007), Editorial Jurídica venezolana, Caracas 2007. pp. 108 ss.

48 Véase lo expresado por el magistrado Francisco Carrasqueño, en la apertura del año judicial en enero de 2008, al explicar que : «no es cierto que el ejercicio del poder político se limite al Legislativo, sino que tiene su continuación en los tribunales, en la misma medida que el Ejecutivo», dejando claro que la «aplicación del Derecho no es neutra y menos aun la actividad de los magistrados, porque según se dice en la doctrina, deben ser reflejo de la política, sin vulnerar la independencia de la actividad judicial». Véase en El Universal, Caracas 29-01-2008.

49 Así lo afirmó el Jefe de Estado, cuando al referirse a una sentencia de la Sala Constitucional muy criticada, en la cual reformó de oficio una norma de la Ley del Impuesto sobre la renta, simplemente dijo: «Muchas veces llegan, viene el Gobierno Nacional Revolucionario y quiere tomar una decisión contra algo por ejemplo que tiene que ver o que tiene que pasar por decisiones judiciales y ellos empiezan a moverse en contrario a la sombra, y muchas veces logran neutralizar decisiones de la Revolución a través de un juez, o de un tribunal, o hasta en el mismísimo Tribunal Supremo de Justicia, a espaldas del líder de la Revolución, actuando por dentro contra la Revolución. Eso es, repito, traición al pueblo, traición a la Revolución.» Discurso del Presidente de la Republica en el Primer Evento con propulsores del Partido Socialista Unido de Venezuela, Teatro Teresa Carreño, Caracas 24 marzo 2007. 
blar siquiera de posibilidad alguna de equilibrio entre poderes y prerrogativas del Estado y derechos y garantías ciudadanas.

La Constitución de Venezuela de 1999, sin duda, formalmente contiene en su texto el elenco de valores del Estado democrático y social de derecho más completo que pueda desearse así como una de las declaraciones de derechos humanos más completas de América Latina, con especificación de los medios para su protección por medio de la acción de amparo, y los recursos ante la Jurisdicción Constitucional y la Jurisdicción Contencioso Administrativa difícilmente contenidos con tanto detalle en otros textos constitucionales. Esas declaraciones, sin embargo, en contraste con la realidad del sistema autoritario, lo que confirman es que para que exista control de la actuación del Estado es indispensable que el Poder Judicial sea autónomo e independiente, y fuera del alcance del Poder Ejecutivo. Al contrario, cuando el Poder Judicial está controlado por el Poder Ejecutivo, las declaraciones constitucionales de derechos se convierten en letra muerta. En otras palabras, para que exista democracia como régimen político en un Estado constitucional y democrático de derecho, no son suficientes las declaraciones contenidas en los textos constitucionales que hablen del derecho al sufragio y a la participación política; ni de la división o separación horizontal del Poder Público, ni de su distribución vertical o territorial del poder público, de manera que los diversos poderes del Estado puedan limitarse mutuamente; así como tampoco bastan las declaraciones que se refieran a la posibilidad de los ciudadanos de controlar el poder del Estado, mediante elecciones libres y justas que garanticen la alternabilidad republicana; mediante un sistema de partidos que permita el libre juego del pluralismo democrático; mediante la libre manifestación y expresión del pensamiento y de la información que movilice la opinión pública; o mediante el ejercicio de recursos judiciales ante jueces independientes que permitan asegurar la vigencia de los derechos humanos y el sometimiento del Estado al derecho. Tampoco bastan las declaraciones constitucionales sobre la «democracia participativa y protagónica» o la descentralización del Estado; así como tampoco la declaración extensa de derechos humanos.

Además de todas esas declaraciones, es necesario que la práctica política democrática asegure efectivamente la posibilidad de controlar el poder, como única forma de garantizar la vigencia del Estado de derecho, y el ejercicio real de los derechos humanos; y que el derecho administrativo pueda consolidarse como un régimen jurídico de la Administración que disponga el equilibrio entre los poderes del Estado y los derechos de los administrados. Para lograr ese equilibrio, sin duda, nuevos derechos ciudadanos deben identificarse en el Estado democrático de derecho y entre ellos, el derecho a la democracia. 
Lamentablemente, en Venezuela, después de cuatro décadas de práctica democrática que tuvimos entre 1959 y 1999, durante esta última década entre 1999 y 2009, en fraude continuo a la Constitución efectuado por el Legislador y por el Tribunal Supremo de Justicia, guiados por el Poder Ejecutivo, a pesar de las excelentes normas constitucionales que están insertas en el Texto fundamental, se ha venido estructurando un Estado autoritario en contra de las mismas, que ha aniquilado toda posibilidad de control del ejercicio del poder y, en definitiva, el derecho mismo de los ciudadanos a la democracia. Ello es lo único que puede explicar que un Jefe de Estado en pleno comienzo del Siglo XXI, pueda llegar a afirmar públicamente retando a sus opositores frente a las críticas por el uso desmedido de poderes de legislación delegada: «Yo soy la Ley. Yo soy el Estado, ${ }^{50} \mathrm{o}$ "La Ley soy yo. El Estado soy yo.»" ${ }^{51}$ Esas frases, repetidas por el Presidente de Venezuela en 2001 y 2008, fueron textualmente atribuidas en 1661 a Luis XIV, al asumir, a la muerte del cardenal Mazarino, el ejercicio del poder sin nombrar un sustituto como ministro de Estado, quien sin embargo nunca la llegó a expresar. ${ }^{52}$ Por ello, pensar sólo que puedan pronunciarse por un Jefe de Estado de nuestros tiempos, lo que pone en evidencia es una tragedia institucional, precisamente caracterizada por la completa ausencia de separación de poderes, de independencia y autonomía del Poder Judicial y, en consecuencia, de gobierno democrático y de derecho ciudadano a la democracia. ${ }^{53}$

New York, febrero de 2009

${ }^{50}$ Expresión del Presidente Hugo Chávez Frías, el 28 de agosto de 2008. Ver en Gustavo Coronel, Las Armas de Coronel, 15 de octubre de 2008: http://lasarmasdecoronel.blogspot.com/ 2008/10/yo-soy-la-leyyo-soy-el-estado.html

51 "La ley soy yo. El Estado soy yo». Véase en El Universal, Caracas 4-12-01, pp. 1,1 and 2,1..

${ }^{52}$ La frase atribuida a Luis XIV cuando en 1661 decidió gobernar solo después de la muerte del Cardenal Mazarin, nunca llegó a pronunciarla. Véase Yves Guchet, Histoire Constitutionnelle Française (1789-1958), Ed. Erasme, Paris 1990, p.8

53 Véase el resumen de esta situación en Teodoro Petkoff, «Election and Political Power. Challenges for the Opposition", in ReVista. Harvard Review of Latin America, David Rockefeller Center for Latin American Studies, Harvard University, Fall 2008, pp. 12. Véase además, Allan R. Brewer-Carías, «Los problemas de la gobernabilidad democrática en Venezuela: el autoritarismo constitucional y la concentración y centralización del poder,» en Diego Valadés (Coord.), Gobernabilidad y constitucionalismo en América Latina, Universidad Nacional Autónoma de México, México 2005, pp. 73-96. 
Title

THE ILLEGITIMATE MUTATION OF THE CONSTITUTION BY THE CONSTITUTIONAL JUDGE AND THE DEMOLITION OF THE RULE OF LAW IN VENEZUELA

\section{Summary}

I. CONSTITUTIONAL SUPREMACY, THE MODIFICATIONS OF THE CONSTITUTION ONLY WITH POPULAR APPROVAL AND THE CONSTITUTIONAL SYSTEMS OF JUSTICE. II. THE ILLEGITIMATE REFORM OF THE CONSTITUTION, AFTER ITS ADOPTION BY THE PEOPLE, BY THE SAME CONSTITUENT NATIONAL ASSEMBLY THAT THE ADOPTED AND ITS LEGITIMATION BY THE CONSTITUTIONAL COURT. III. THE ILLEGITIMATE MUTATION MADE BY THE CONSTITUTIONAL JUDGE OF THE EFFECTS OF THE RECALL ELECTION-REFRENDA OF OFFICES FILLED BY POPULAR VOTE. IV. THE ILLEGITIMATE MUTATION MADE BY THE CONSTITUTIONAL JUDGE OF THE CONSTITUTIONAL RANK OF THE TREATIES RELATING HUMAN RIGHTS. V. THE ILLEGIMATE MUTATION MADE BY THE CONSTITUTIONAL JUDGE OF THE PRINCIPLE OF THE REPUBLICAN ALTERNABILITY, THE CONSTITUTIONAL AMENDMENT TO ESTABLISH THE INMEDIATE AND CONTINUING RE-ELECTION OFFICIALS ELECTED AND THE MODIFICATION OF THE EFFECTS OF THE POPULAR REJECTION TO CONSTITUTIONAL REFORMS. VI. THE ILLEGITIMATE CONSTITUTIONAL MUTATION BY THE CONSTITUTIONAL JUDGE OF THE PROHIBITION OF THE PUBLIC FINANCING TO THE ACTIVITIES OF THE POLITICAL PARTIES. FINAL APPRECIATION.

\section{Resumen}

Este artículo tiene por objeto analizar algunas de las ilegítimas mutaciones constitucionales efectuadas por la Sala Constitucional del Tribunal Supremo de Justicia de Venezuela, al decidir recursos autónomos de interpretación constitucional que han sido interpuestos por el Poder Ejecutivo, y que han trastocado los cimientos del Estado de derecho. Un recurso judicial como el de interpretación abstracta de la Constitución, creado por la Sala Constitucional sin soporte en la Constitución, en manos de un Juez Constitucional totalmente dependiente del mismo Poder Ejecutivo, sin autonomía ni independencia algunas, ha 
resultado ser un instrumento utilizado para cambiar y ajustar la Constitución a la voluntad del Ejecutivo, al margen de los procedimientos de reforma y de la voluntad del poder, afianzando el autoritarismo.

\begin{abstract}
This article is devoted to analyze some of the illegitimate constitutional mutations made in Venezuela by the Constitutional Chamber of the Supreme Tribunal of Justice, deciding petitions for the abstract interpretation of the Constitution filled by the Executive, which have disrupted the rule of law. A judicial mean of this kind, seeking to obtain abstracts interpretation of the Constitution that has been created by the same Constitutional Chamber without constitutional support, in hands of a Constitutional Jurisdiction completely dependent of the same Executive power, without autonomy and independence, has resulted in an instrument that has been used in order to change and adjust the Constitution to the will of the Executive, by-passing the constitutional review procedures and the popular will, and securing the authoritarian government.
\end{abstract}

\title{
Palabras clave
}

Estado de derecho, reforma constitucional, mutación constitucional, jurisdicción constitucional, gobierno autoritario, separación de poderes

\section{Key words}

Rule of law, Constitutional review, Constitutional mutation, Constitutional jurisdiction, Authoritarian government, Separation of powers 